\title{
COMBINED ANALYSIS OF RADARSAT-2 SAR AND SENTINEL-2 OPTICAL DATA FOR IMPROVED MONITORING OF TUBER INITIATION STAGE OF POTATO
}

\author{
Dipankar Mandal ${ }^{1, *}$, Vineet Kumar $^{1}$, Y. S. Rao ${ }^{1}$, Avik Bhattacharya ${ }^{1}$, Soumen Bera ${ }^{2}$, Manoj Kumar Nanda ${ }^{3}$ \\ ${ }^{1}$ Microwave Remote Sensing Lab, Centre of Studies in Resources Engineering, \\ Indian Institute of Technology Bombay, Mumbai, 400076 INDIA \\ dipankar_mandal@iitb.ac.in; vineetk008@iitb.ac.in; ysrao@csre.iitb.ac.in; avikb@csre.iitb.ac.in \\ ${ }^{2}$ College of Agriculture, Bidhan Chandra Krishi Viswavidyalaya, \\ Bardhaman, West Bengal, 713101 INDIA - soumen.bckv@gmail.com \\ ${ }^{3}$ Dept. of Agricultural Meteorology and Physics, Bidhan Chandra Krishi Viswavidyalaya, \\ Mohanpur, West Bengal, 741252 INDIA - mknandabckv@ rediffmail.com
}

Commission V, SS: Natural Resources Management

KEY WORDS: Crop dynamics, Potato, SAR, RADARSAT-2, Sentinel-2, Red edge

\begin{abstract}
:
Tuber initiation and tuber bulking stages are critical part of various phenological phases for potato production. Tuber initiation covers the period from the formation of spherical rhizome ends, the flowering and the start of tuber bulking. In general, the tuberization spans from 3 to 5 weeks after emergence and ends with the row closer i.e. canopies in adjacent rows touch each other across the furrow. Hence, this rapid growth seeks critical agronomic management practices such as irrigation and fertilization. It majorly influences the growth of stems, foliar area, dry weight and number of tubers particularly at the phase of tuber initiation. During these phenological stages, potato crops are susceptible to the infestation of late blight diseases caused by Phytophthora infestans and largely affects the potato production. Thus identifying the crop risk using remote sensing approaches can provide an efficient potato growth monitoring framework. In the context of monitoring crop dynamics, quad-pol Synthetic Aperture Radar (SAR) data has proven to be effective due to its sensitivity towards dielectric and geometric properties. In addition to SAR data, optical remote sensing data derived vegetation information can provide an improved insight into crop growth when combined with SAR data. In this research, quad-pol RADARSAT-2 and Sentinel-2 optical data are analyzed to monitor potato tuberization phase over Bardhaman district in the state of West Bengal, which is one of the major potato growing regions in India. The proposed approach uses polarimetric parameters such as backscatter intensities, ratio $\left(\mathrm{HH} / \mathrm{VV}, \mathrm{VH} / \mathrm{VV}\right.$, linear depolarization ratio), and co-pol correlation $\left(\rho_{H H-V V}\right)$ along with the vegetation indices derived from the Sentinel-2 data for understanding the spatio-temporal dynamics. The initial results show a promising accuracy in monitoring the dynamics of potato tuberization. Integration of such earth observation (EO) data, in conjunction with in-situ field measurements, might significantly enhance the current capabilities for crop monitoring.
\end{abstract}

\section{INTRODUCTION}

Monitoring of crop dynamics is essential for timely information about crop condition and planning various agronomic management. Of note, it is important to characterize critical phenology stages of the crop as they are directly related to the yield (Mo et al. 2017, Ritchie et al. 1998). For instance, tuber initiation and tuber bulking stages are critical of various phenological phases for potato production. Tuber initiation covers the period from the formation of spherical rhizome ends, the flowering and the start of tuber bulking. In general, the tuberization spans from 3 to 5 weeks after emergence and ends with the row closer, i.e. canopies in adjacent rows touch each other across the furrow. Hence, this rapid growth seeks critical agronomic management practices such as irrigation and fertilization. It primarily influences the growth of stems, foliar area, dry weight and number of tubers particularly at the phase of tuber initiation. During these phenological stages, potato crops are particularly vulnerable to the infestation of late blight diseases caused by Phytophthora infestans and primarily affects the potato production (Basu et al., 2007, Arora et al. 2014).

Nevertheless, characterizing crop growth stages and favorable

\footnotetext{
${ }^{*}$ Corresponding author: Dipankar Mandal
}

conditions for crop diseases is challenging due to varying plantation period and field conditions. It becomes more challenging for monitoring over a larger spatial extent. In this context, remote sensing data has the potential to provide accurate crop condition information in spatial as well as temporal scale. Optical remote sensing data derived vegetation information is found to be suitable for crop growth monitoring and has good correlation with yield (Benedetti and Rossini. 1993; Myneni et al. 1995). The response of optical data in terms of reflectance links between the photosynthetic and chemical properties of the plant green elements through vegetation indices. Conversely, the Synthetic Aperture Radar (SAR) data has drawn considerable attention for agricultural applications due to its all-weather monitoring and sensitivity towards dielectric and geometric properties (SteeleDunne et al. 2017).

In addition, several studies confirm that SAR observables are responsive to crop phenological changes in physiological structures (Lopez-Sanchez et al. 2012, Hariharan et al., 2018). Till date, few studies have been using dense time series SAR data for crop monitoring. However, a combined analysis of SAR and optical data can provide an insight to critical stages of crop (Clevers and Van Leeuwen, 1996, McNairn et al. 2009, Veloso et al. 2017). Hence, the current research aims to analyze and interpret 


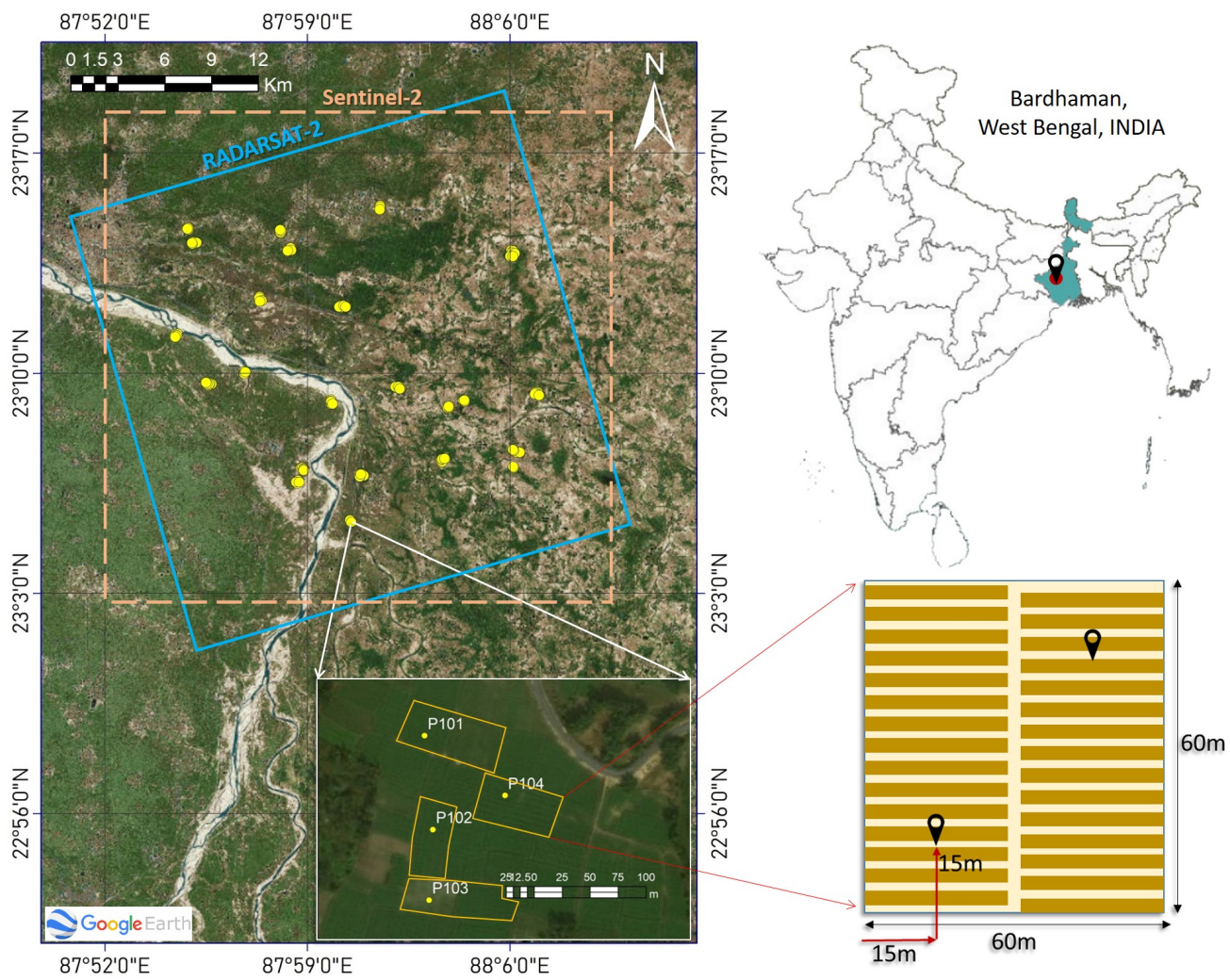

Figure 1. Test site with sampling locations. The cyan and light brown box defines the RADARSAT-2 and subset of Sentinel-2 coverage, respectively.

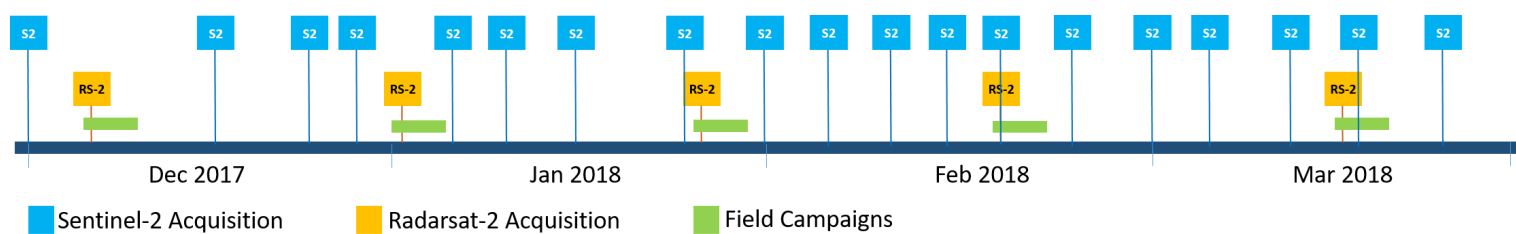

Figure 2. Calendar of the Sentinel-2 and RADARSAT-2 data acquisitions along with field campaigns over the test site.

time series of RADARSAT-2 and Sentinel-2 data for tuberization of potato. Furthermore, the potential of an integrated analysis of polarimetric parameters and vegetation indices for characterization of the tuberization stage is assessed.

\section{MATERIALS AND METHODS}

\subsection{Study Area and Cultivation Practices}

The present research is conducted over test site situated in the Damodar-Ajay river basin of East Bardhaman district in the state of West Bengal, India as shown in Figure 1 The major soil texture is sandy-loam in this river basin resulting in well-drained soil condition. The test site covers an area of $25 \times 25 \mathrm{~km}^{2}$ and is characterized by major annual crops viz. rice, potato, mustard, sesame and jute (Prashnani et al. 2014. Mandal et al. 2018). However, the present research is concentrated on the winter season (December-March) crop Potato (Solanum tuberosum). In this test site, the potato has a wide plantation calendar extending from November to December. In general, the potato is planted after harvesting of rice. Thus, delay in harvest of rice due to unexpected precipitation at its harvest period usually results in a late planting of potato than its optimum time for planting (Mid of November).

Due to the variability of the plantation period, adaptation of several potato plant varieties, e.g., Khufri Joyti, Kufri Chandramukhi, Kufri Pukhraj, etc. are likely planted in this area (Marwaha et al. 2007). Amongst these varieties, Khurfi Chandramukhi has been reported as more affected by late blight diseases caused by Phytophthora infestans and primarily affects the potato production in this test site (Basu et al. 2007).

In general, potato is planted directly in the field in ridge and furrow system. In this cultivation practices, a spacing of $45-60 \mathrm{~cm}$ between rows and $20 \mathrm{~cm}$ between plants is adopted. The total irrigation water requirement of potato varies between $350-550 \mathrm{~mm}$ depending upon soil type and climate. Pre-Planting irrigation is advantageous for uniform germination of potato. Second irrigation is given after about a week and subsequent irrigations as and when required. However, irrigation is essential at critical stages in crop development, i.e., stolon formation, tuber initiation, and tuber development stage of the potato plant.

In addition, inter-cultural practices, such as hoeing and weed- 
ing followed by earthing up, are desirable when potato plants are about a month old. The first earthing-up is generally performed when the plants are $\sim 15$ to $25 \mathrm{~cm}$ high. The second earthing up is often done to cover up the tubers adequately. Harvesting of potatoes is done before the maximum soil temperature rises above $26-30^{\circ} \mathrm{C}$ during the end of February to avoid rotting of tubers due to high temperatures in March/April. The general practice is to stop the last irrigation before 10-15 days of harvesting of tubers, which allows tuber skin to become firm and tubers do not get bruised on harvesting (Chadha. 1993.

\subsection{Sampling Strategy}

In-situ measurements were collected intensively from December 2017 to March 2018 with several field campaigns. During the campaign, $\sim 68$ fields were selected for sampling. The nominal size of each field was $\sim 60 \mathrm{~m} \times 60 \mathrm{~m}$. During these campaigns, insitu measurements of bio-geophysical parameters viz. biomass, Plant Area Index(PAI), plant height, phenology (BBCH scale), plant density and soil moisture were collected at different phenological stages of potato in two sampling location at each field as shown in Figure 1. Above ground biomass was collected by destructive sampling. At each sample location, 10 plants $(5$ plants/row) were harvested from two consecutive rows. Plant area index (PAI) was measured by processing digital hemispherical photographs in CANEYE software (INRA 2017). Soil moisture was measured in two locations within a field using the Theta Probe. The detailed description of soil and vegetation sampling can be found in the campaign experimental plan (Mandal et al. 2017).

\subsection{Satellite Data and Image Processing}

In this study, five RADARSAT-2 fine quad-pol (FQ17) images in single look complex (SLC) format are utilized. All these images were acquired during the intensive observation periods of the field campaign. In a preprocessing step, the covariance matrix $\langle[\mathbf{C}]\rangle$ were generated from the scattering matrix of SLC images. Subsequently, the multi-temporal images were speckle filtered using a $3 \times 3$ Refined Lee filter and were co-registered. Finally, polarimetric parameters such as backscatter intensities $\left(\sigma^{0}\right)$, cross-pol ratio $\mathrm{HV} / \mathrm{VV}$, linear depolarization ratio $2 \sigma_{H V}^{0} /\left(\sigma_{H H}^{0}+\sigma_{V V}^{0}\right)$, and co-pol correlation for each site were calculated as the average of a $3 \times 3$ window centred on each site from the elements of the covariance matrix $\langle[\mathbf{C}]\rangle$.

Along with the SAR images, twelve Sentinel-2 time series (December 2017- March 2018) images (Level 1C) were acquired over this study area as shown in Figure 2.3. Preprocessing steps, e.g. atmospheric corrections (Sen2Cor), spatial resampling to $20 \mathrm{~m}$ resolution was performed in ESA's Sentinel Application Platform (SNAP) toolbox (ESA 2014). Three vegetation indices, i.e. Normalized Difference Vegetation Index (NDVI), Normalized Difference Water Index (NDWI), and Normalized Difference Index 45 (NDI45) were derived from the pre-processed Sentinel2 for understanding the spatio-temporal dynamics (Frampton et al. 2013). Finally, the Vegetation Indices (VIs) for every sampling locations were calculated as the average of a 3 window centred on each location for all dates.

\section{RESULTS AND DISCUSSION}

Potato was planted as seed tubers in the majority of fields with a ridge-furrow cultivation system during the 1 st-2nd week of December 2017. Upon emergence, plants develop a main-stem with leaves and continue developing leaves in several primary and secondary leaflets up to the inflorescence during the 3 rd week after plantation. In a concurrent development process, tuber initiation starts by the formation of tuber beneath the ground and covers the period up to the appearance of the first flower (in most varieties) to full bloom followed by tuber bulking stage. However, as a tuber crop, stolon and tuber initiation provide a distinct developmental stage but are difficult to observe as they occur below the ground. Thus for Earth Observation (EO) data, a proxy of plant growth would be above ground canopy characteristics. A rapid increase in plant leaf area often observed during the tuber initiation stage and ends with peak aboveground biomass accumulation and canopy closure during tuberization. During the tuber bulking stage, plant vegetative growth slows down and the plant growth shifts from vegetative elements to tubers. During senescence, the lower leaves turn yellow and fall from the plant. Subsequently, progressive yellowing of leaves, as well as stems, starts with a decrease in PAI and biomass. The analysis of SAR and optical data with phenological development are separated into two groups. Group-1 includes field no. P03, P11 and P12 as shown in Figure 3 and field no. P04, P05 and P13 in Group-2 as shown in Figure 4 These groups are solely based on in-situ measurements which indicate that early plantation was practiced in Group-1, whereas Group-2 contains late plantation fields.

\subsection{Responses to Group-1 (Early plantation) Potato}

SAR backscatter responses and VIs for each of the fields throughout the phenological stages are presented in Figure 3 Changes in aboveground biomass (vegetation water content, $\mathrm{kgm}^{-2}$ ) and Plant Area Index (PAI) within development stages were measured during the field campaigns. The light green rectangular box in the PAI/VWC plot represents the tuber initiation stage which occurred during the 1st-3rd week of January 2018 for Group1 fields. The backscatter intensities $\left(\sigma_{H H}^{0}, \sigma_{V V}^{0}\right.$ and $\left.\sigma_{H V}^{0}\right)$ decreases as plant canopy grows, which indicates attenuation of $\mathrm{C}$-band signal. The changes in the responses of backscatter ratio parameters and $\rho_{H H-V V}$ are apparent during the tuberization stage. In general, a high correlation between the co-pol channels ( $\left.\rho_{H H-V V} \sim 1\right)$ can be observed at the initial growth stage and harvest period of the crop. It is usually characterized by dominating surface scattering from the underlying soil surface. However, the coherence between the co-pol channels drops as the leaf development ends thereby showing an increase in the diffuse scattering component. VIs derived from Sentinel-2 optical data are also in agreement with peak biomass accumulation and PAI for all fields. Conversely, VIs started decreasing after tuberization as plant progressed into tuber bulking.

A distinct difference in responses for field no. P03 is apparent after 19 February 2018. Although, other fields (P11 and P12) were harvested; the $\mathrm{P} 03$ field was cultivated with ground pumpkin $(\mathrm{Cu}$ curbita moschata) which grows laterally after harvest of potato. Thus an increase in VIs is expected from the vegetative growth of pumpkin in $\mathrm{P} 03$.

\subsection{Responses to Group-2 (Late plantation) Potato}

As compared to early planted potato fields, the Figure 4 represents responses of SAR and optical VIs for comparatively late planted potato. The late plantation of potato is apparent in PAI and biomass plots with the occurrence of peak biomass during the first week of March 2018. The radar backscatter intensities $\left(\sigma_{H H}^{0}, \sigma_{V V}^{0}\right.$ and $\left.\sigma_{H V}^{0}\right)$ and ratio parameters follows the similar trend. The decrease in co-pol correlation $\left(\rho_{H H-V V}\right)$ is evident 


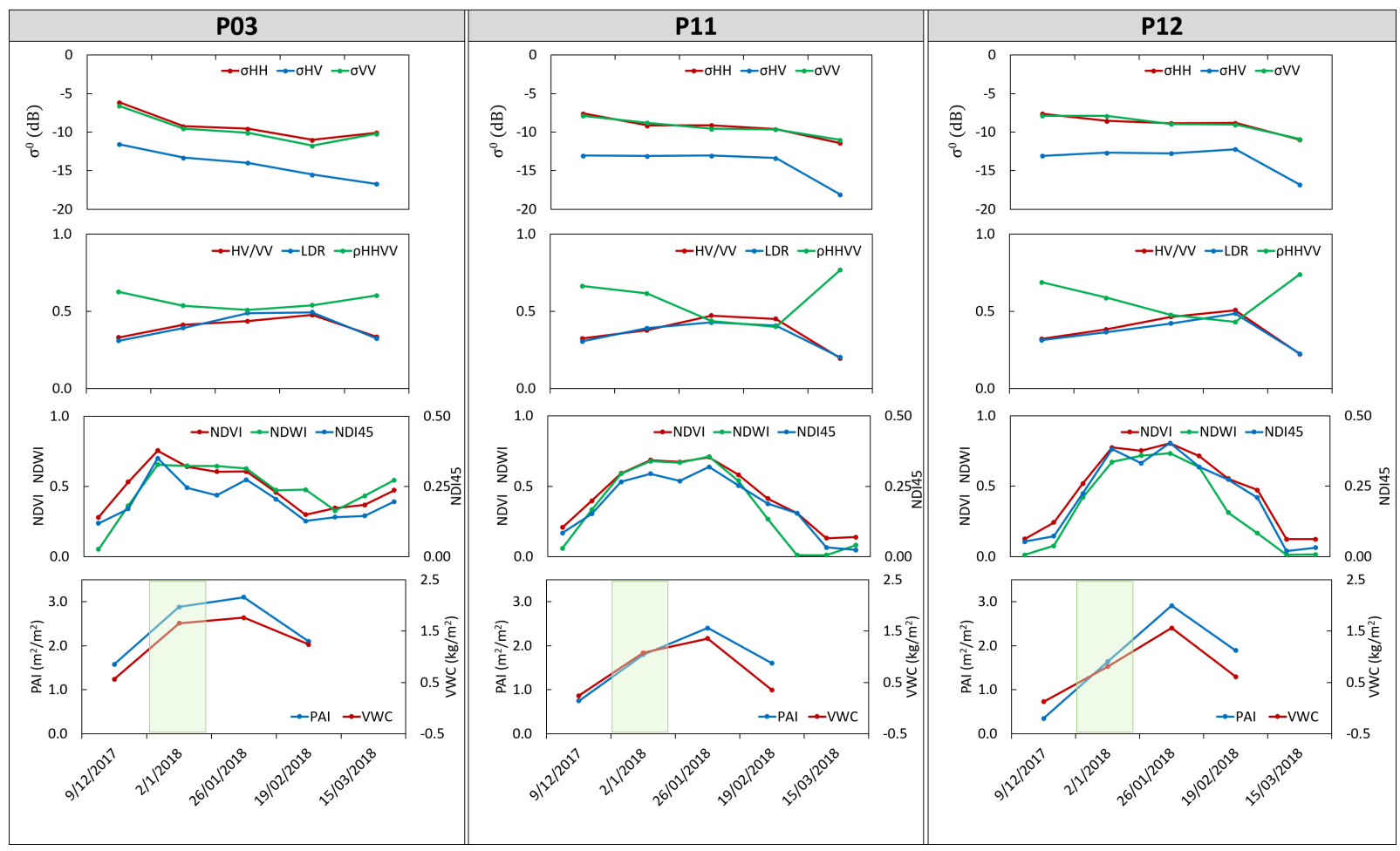

Figure 3. Observations over the early planted potato fields: temporal behavior of optical NDVI, NDI45, NDWI, radar $\sigma_{H H}^{0}, \sigma_{V V}^{0}$ and $\sigma_{H V}^{0}, H V / V V, L D R, \rho_{H H-V V}$, and Plant Area Index (PAI), Vegetation water content (VWC) over the test site.

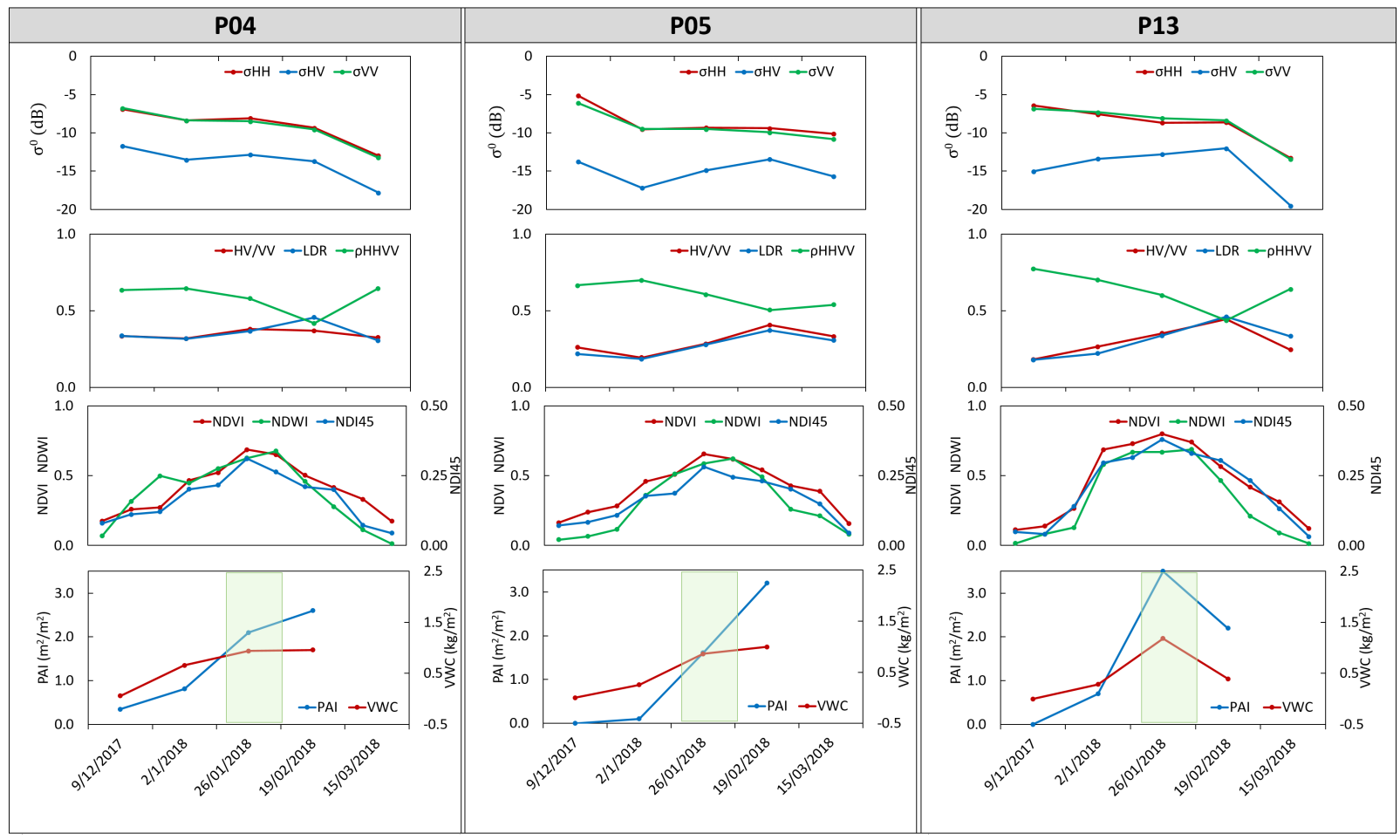

Figure 4. Observations over the late planted potato fields: temporal behavior of optical NDVI, NDI45, NDWI, radar $\sigma_{H H}^{0}, \sigma_{V V}^{0}$ and $\sigma_{H V}^{0}, H V / V V, L D R, \rho_{H H-V V}$, and Plant Area Index (PAI), Vegetation water content (VWC) over the test site.

up to tuberization as canopy closer increased with increase VWC and PAI.

The backscatter intensities $\left(\sigma_{H H}^{0}, \sigma_{V V}^{0}\right.$ and $\left.\sigma_{H V}^{0}\right)$ decreases as plant canopy grows, which indicates attenuation of C-band signal. The changes in the responses of backscatter ratio parameters and $\rho_{H H-V V}$ are apparent during the tuberization stage. The $\rho_{H H-V V}$ started increasing as crop senescence, indicated similar 
$\mathrm{HH}$ and VV response (Hariharan et al. 2018). VIs derived from Sentinel-2 optical data are also in agreement with peak biomass accumulation and PAI for all fields. Conversely, VIs started decreasing after tuberization as plant progressed into tuber bulking. It is important to note that a sharp decrease in PAI and VWC was observed for field no. P13 during the tuberization stage. It has confirmed from the in-situ measurements that a late blight disease severely affected the field no. P13. This disease affects entire leaflets and stem, and subsequently, a distinctive fatigue was observed in the entire affected field (Arora et al. 2014). A sharp decrease in VIs is also apparent due to the late blight diseases over field no. P13.

These findings suggest that combine analysis of SAR observable and optical data derived indices may be able to characterize potato tuberization stage. Monitoring of this critical phenological stage is essential as the yield largely depends on formation and maturity of tubers. This stage also indicates critical agronomic operations, e.g. irrigation and fertilizer (primarily nitrogen group) application. Of note, high humidity and warmer temperature (due to cloudy daytime hours during a winter season) generally acts as a favorable condition of diseases (early and late blight disease) outbreak during the tuberization stages (Hide and Lapwood 1992). Thus care should be taken at these critical stages to avoid yield loss.

\section{CONCLUSIONS}

In this research, a time series of RADARSAT- 2 and Sentinel2 data were used to assess the potential of SAR observables and optical data-driven VIs for potato tuberization stage monitoring. The time series of optical NDVI, NDI45, NDWI and radar backscatter intensities $\left(\sigma_{H H}^{0}, \sigma_{H V}^{0}, \sigma_{V V}^{0}\right)$, ratios $(\mathrm{HV} / \mathrm{VV}$ and LDR), and co-pol correlation $\left(\rho_{H H-V V}\right)$ were analyzed and physically interpreted with the support of in-situ measurements (PAI and vegetation water content (VWC)). These findings suggest that combined analysis of SAR observable and optical data derived indices is able to characterize potato tuberization stage.

\section{ACKNOWLEDGEMENTS}

The authors would like to thank the Canadian Space Agency and MAXAR Technologies Ltd. (formally MDA) for providing RADARSAT-2 data through SOAR-EI-5459. This research work is funded partly by the Indian Space Research Organisation (ISRO) sponsored project no. 17ISROC007.

\section{References}

Arora, R., Sharma, S. and Singh, B., 2014. Late blight disease of potato and its management. Potato Journal.

Basu, A., Maiti, M. et al., 2007. Epidemiological study on late blight disease of potato caused by Phytophthora infestans in West Bengal. Journal of Mycopathological Research 45(1), pp. 90-93.

Benedetti, R. and Rossini, P., 1993. On the use of NDVI profiles as a tool for agricultural statistics: the case study of wheat yield estimate and forecast in Emilia Romagna. Remote Sensing of Environment 45(3), pp. 311-326.

Chadha, K., 1993. Advances in horticulture. Malhotra Publ. House.

Clevers, J. and Van Leeuwen, H., 1996. Combined use of optical and microwave remote sensing data for crop growth monitoring. Remote Sensing of Environment 56(1), pp. 42-51.
ESA, 2014. Sentinel-2 Toolbox - ESA Sentinel. https://sentinel.esa.int/web/sentinel/toolboxes/sentinel-2.

Frampton, W. J., Dash, J., Watmough, G. and Milton, E. J., 2013. Evaluating the capabilities of Sentinel-2 for quantitative estimation of biophysical variables in vegetation. ISPRS journal of photogrammetry and remote sensing 82, pp. 83-92.

Hariharan, S., Mandal, D., Tirodkar, S., Kumar, V., Bhattacharya, A. and Lopez-Sanchez, J. M., 2018. A novel phenology based feature subset selection technique using random forest for multitemporal PolSAR crop classification. IEEE Journal of Selected Topics in Applied Earth Observations and Remote Sensing pp. 1-15. DOI: 10.1109/JSTARS.2018.2866407

Hide, G. and Lapwood, D., 1992. Disease aspects of potato production. In: The Potato Crop, Springer, pp. 403-437.

INRA, 2017. CAN-EYE. https://www6.paca.inra.fr/can-eye.

Lopez-Sanchez, J. M., Cloude, S. R. and Ballester-Berman, J. D., 2012. Rice phenology monitoring by means of SAR polarimetry at X-band. IEEE Transactions on Geoscience and Remote Sensing 50(7), pp. 2695-2709.

Mandal, D., Kumar, V., Bhattacharya, A., Rao, Y., S., Bera, S. and Nanda, M., K., 2017. Experimental Field Campaigns — Bardhaman Test Site. http://mrslab.in/FieldCampaign/TSBWN.

Mandal, D., Kumar, V., Bhattacharya, A., Rao, Y. S., Siqueira, P. and Bera, S., 2018. Sen4rice: A processing chain for differentiating early and late transplanted rice using time-series Sentinel-1 SAR data with Google Earth Engine. IEEE Geoscience and Remote Sensing Letters pp. 1-5. DOI: 10.1109/ LGRS. 2018.2865816

Marwaha, R, S., Singh, S, V., Pandey, S, K., Kumar, D., Kumar, P., Mehta, A. and Ezekiel, R., 2007. Scenario of potato production and processing in West Bengal. Technical Report 85, Central Potato Research Institute, ICAR.

McNairn, H., Champagne, C., Shang, J., Holmstrom, D. and Reichert, G., 2009. Integration of optical and Synthetic Aperture Radar (SAR) imagery for delivering operational annual crop inventories. ISPRS Journal of Photogrammetry and Remote Sensing 64(5), pp. 434-449.

Mo, F., Wang, J.-Y., Li, F.-M., Nguluu, S. N., Ren, H.-X., Zhou, H., Zhang, J., Kariuki, C. W., Gicheru, P., Kavagi, L. et al., 2017. Yield-phenology relations and water use efficiency of maize (Zea mays L.) in ridge-furrow mulching system in semiarid east African Plateau. Scientific Reports 7(1), pp. 3260.

Myneni, R. B., Hall, F. G., Sellers, P. J. and Marshak, A. L., 1995. The interpretation of spectral vegetation indexes. IEEE Transactions on Geoscience and Remote Sensing 33(2), pp. 481486.

Prashnani, M., Singh, D. K., Joshi, R. and Ray, S., 2014. Understanding Crop Growing Pattern in Bardhaman district of West Bengal using Multi-Date RISAT 1 MRS data. The International Archives of Photogrammetry, Remote Sensing and Spatial Information Sciences 40(8), pp. 861.

Ritchie, J., Singh, U., Godwin, D. and Bowen, W., 1998. Cereal growth, development and yield. In: Understanding options for agricultural production, Springer, pp. 79-98.

Steele-Dunne, S. C., McNairn, H., Monsivais-Huertero, A., Judge, J., Liu, P.-W. and Papathanassiou, K., 2017. Radar remote sensing of agricultural canopies: A review. IEEE Journal of Selected Topics in Applied Earth Observations and Remote Sensing 10(5), pp. 2249-2273.

Veloso, A., Mermoz, S., Bouvet, A. Le Toan, T., Planells, M., Dejoux, J.-F. and Ceschia, E., 2017. Understanding the temporal behavior of crops using Sentinel-1 and Sentinel-2-like data for agricultural applications. Remote Sensing of Environment 199, pp. 415-426. 